\title{
Cardiac Energetics in Presence of Lung Assist Devices: In Silico Study
}

\author{
Claudio De Lazzari1 ${ }^{1,2}$, Bernhard Quatember ${ }^{3}$ \\ ${ }^{1}$ Institute of Clinical Physiology U.O.S. of Rome (C.N.R.), Rome, Italy \\ ${ }^{2}$ National Institute for Cardiovascular Research (I.N.R.C.), Bologna, Italy \\ ${ }^{3}$ Univ.-Klinik für Radiologie, Innsbruck Medical University, Innsbruck, Austria \\ Email: claudio.delazzari@ifc.cnr.it
}

How to cite this paper: De Lazzari, C. and Quatember, B. (2016) Cardiac Energetics in Presence of Lung Assist Devices: In Silico Study. Modeling and Numerical Simulation of Material Science, 6, 41-57.

http://dx.doi.org/10.4236/mnsms.2016.63005

Received: July 2, 2016

Accepted: July 10, 2016

Published: July 28, 2016

Copyright $\odot 2016$ by authors and Scientific Research Publishing Inc. This work is licensed under the Creative Commons Attribution International License (CC BY 4.0).

http://creativecommons.org/licenses/by/4.0/

\begin{abstract}
The treatment with a mechanical ventilator is required whenever a patient's respiratory system becomes unable to keep the concentrations of $\mathrm{O}_{2}$ and $\mathrm{CO}_{2}$ in blood at tolerable levels. However, in particular cases, the thoracic artificial lung (TAL) can be regarded as a viable alternative to mechanical ventilation (MV). We aim at studying the effects of mechanical ventilators and thoracic artificial lungs devices will have on the cardiovascular system. We will give careful consideration to cardiovascular energetic parameters, such as left and right ventricular external work, pressure-volume area, and cardiac mechanical efficiency. We simulated both, mechanically ventilated patients who are not subject to the application of an artificial lung and patients who are provided with a thoracic artificial lung (TAL). In the case of a thoracic artificial lung, we involved in our simulation studies all the usual operating modes of a TAL, viz. series mode, parallel mode, and hybrid mode of the TAL with regard to the native lung. In particular, the presented simulation results will contribute to elucidate the specific characteristics of each of the aforementioned operating modes. Generally, the energetic variables are influenced by different values of input TAL resistance in both modes: parallel and in series. In this paper, we concentrated on simulation studies of the effects evoked by TAL assistance on cardiac energetic and some other important circulatory parameters. The simulation results presented show that at all modes of TAL assistance exists a strong dependency on the TAL input variables and on the value of the mean intrathoracic pressure which has been assumed for a given situation.
\end{abstract}

\section{Keywords}

Cardiovascular System, Numerical Model, Simulation, Mechanical Ventilation, Thoracic Artificial Lung, Ventricular Energetics 


\section{Introduction}

We will deal here with specific problems, which arise when clinicians use mechanical ventilators (MVs) and thoracic artificial lungs (TALs) in the treatment of patients suffering from respiratory failure and related serious diseases, such as chronic obstructive pulmonary disease (COPD), acute respiratory distress syndrome (ARDS), and pneumonia. As a general rule, the treatment with a mechanical ventilator is required whenever a patient's respiratory system becomes unable to keep the concentrations of $\mathrm{O}_{2}$ and $\mathrm{CO}_{2}$ in blood at tolerable levels. A ventilator may also be necessary for patients who need ventricular assist device (VAD) assistance [1]. However, in particular cases, the thoracic artificial lung (TAL) can be regarded as a viable alternative to mechanical ventilation (MV). There are even patients with severely damaged lung function where MV is considered inappropriate. Under these circumstances, the treatment with an artificial lung (preferably TAL) is mandatory.

Both the application of a MV of the respiratory system and the usage of a TAL give rise to specific interactions with other organs, especially with the cardiovascular system [2] [3]. Moreover, these interactions will be strongly dependent on the modes of operation of these devices. These interactions may cause complications and other adverse effects. We will focus here on the effects of the usage of the aforementioned devices (MV and TAL) will have on the cardiovascular system in terms of energetic parameters. A fair knowledge of the just mentioned adverse effects on the cardiovascular system is highly important to clinicians who are responsible for the medical attendance of patients subject to MV and for the treatment with an artificial lung, since during such medical treatments difficult medical decisions must be made at all times. Moreover, an appropriate mode of operation of the devices must be set to avoid critical functional states of the cardiovascular system. We aim at providing clinicians with a fair quantitative knowledge of the effects the usage of MVs and TALs will have on the cardiovascular system. In order to achieve this purpose, we carried out computer simulation studies with our numerical cardiovascular simulator CARDIOSIM ${ }^{\oplus}$ [4] [5]. Recently, we designed a special module for TAL [6] [7] as an extension of CARDIOSIM ${ }^{\odot}$ and configured the software for our investigations in a straightforward manner by appropriately interconnecting the already existing individual software modules and the newlydeveloped module for the TAL. The TAL can be arranged either in series or in parallel mode, whereby both modes are involving the native lung. Moreover, a hybrid mode is also possible [8] [9] [10] which also involves the native lung. By using the augmented CARDIOSIM $^{\oplus}$ system, we simulated the interactions of MVs and TALs on the cardiovascular system for all possible modes of operation. In particular, we determined specific energetic and hemodynamic quantities and parameters of the cardiovascular system influenced by MV, such as left and right ventricular external work (EW), pressurevolume area (PVA), cardiac mechanical efficiency (CME) [11], cardiac output (CO), and mean pulmonary arterial pressure (PAP). The simulation results may help experienced and especially novice clinicians to acquire prior knowledge which will help them to appropriately treat the patient. In our development, we put much emphasis to 
the clinical aspects of our simulation facilities.

\section{Materials and Methods}

As already mentioned earlier, we aim at studying how and what extent either mechanical ventilation or the usage of a thoracic artificial lung will affect the patient's cardiovascular system by carrying out computer simulations. The already existing numerical simulator CARDIOSIM ${ }^{\circ}$ is a simulator for the cardiovascular system which was developed earlier [4] [5] [6]. It was successfully used for simulations of the cardiovascular system.

CARDIOSIM $^{\oplus}$ has a modular structure. Its individual modules served as the core programs of our simulation software system. To achieve the specific goals of our studies, it was solely necessary to extend the already existing software modules of CARDIOSIM $^{\odot}$ by developing a module for the TAL and to integrate this newly-developed software module into the already existing CARDIOSIM ${ }^{\odot}$ software structure.

Subsequently, we will give an overview of CARDIOSIM ${ }^{\odot}$; for a more detailed description, please refer to [4] [5] [6] [7] [12] [13]. This overview will be followed by a more detailed description of the newly-developed TAL software module and its integration into CARDIOSIM ${ }^{\odot}$.

\subsection{Modules "Left Heart" and "Right Heart"}

These (software) modules are based on mathematical models which describe the behavior of the ventricles, the atria and the septa. They are mainly based on a variable elastance modeling approach; however, we assumed that the atrial septa are rigid [12] [14]. For the left (right) ventricle the time-varying ventricular elastance $\operatorname{elv}(t)(\operatorname{erv}(t))($ Figure $1($ Panel $\mathrm{A})$ ) is described as a function of the left (right) ventricular end-systolic elastance Elvs (Ervs), the left (right) ventricular end-diastolic elastance Elvd (Ervd) and the left (right) activation function $\operatorname{alv}(t)(\operatorname{arv}(t))$ as follows:

$$
\begin{gathered}
\operatorname{elv}(t)=\operatorname{Elvd}+\frac{\text { Elvs }- \text { Elvd }}{2} \operatorname{alv}(t) \\
\operatorname{erv}(t)=\operatorname{Ervd}+\frac{\text { Ervs }- \text { Ervd }}{2} \operatorname{arv}(t) \\
\operatorname{alv}(t)=\operatorname{arv}(t)= \begin{cases}1-\cos \left(\frac{t}{T_{T}} \pi\right) & 0 \leq t \leq T_{T} \\
1+\cos \left(\frac{t-T_{T}}{T_{T E}-T_{T}} \pi\right) & T_{T}<t \leq T_{T E} \\
0 & T_{T E}<t \leq T_{D}\end{cases}
\end{gathered}
$$

where $T_{D}$ is the duration of the ECG signal for a cardiac cycle (heart period), $T_{T E}$ is the end of ventricular systole and $T_{T}$ is the $T$-wave peak time.

To model the behavior of the septum (Figure 1 (Panel A)) we use the following equation:

$$
e_{S P T}(t)=E d_{S P T}+\frac{E s_{S P T}-E d_{S P T}}{2} a_{S P T}(t)
$$



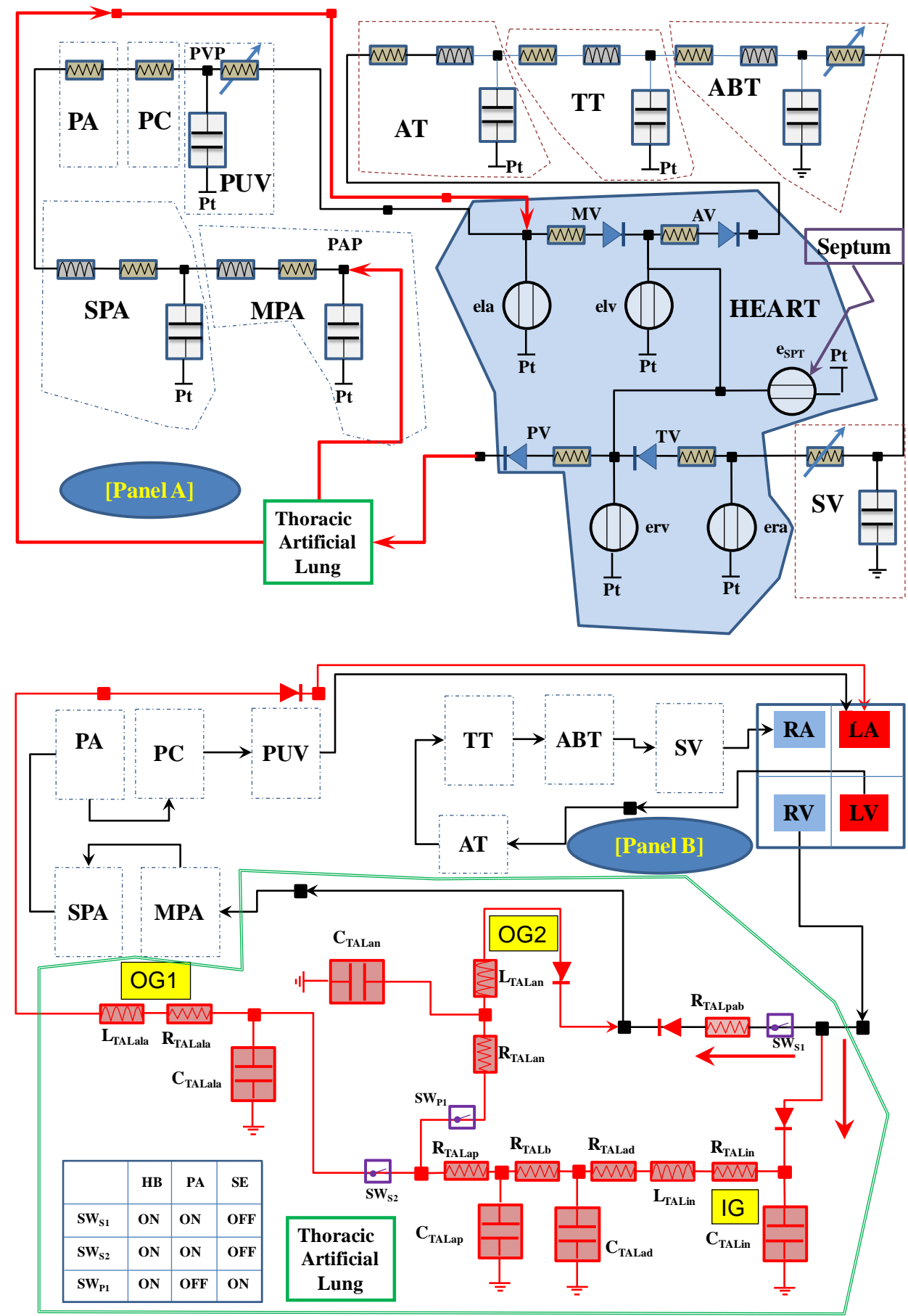

Figure 1. Panel A: Electric analogue of the cardiovascular system with TAL. AT, TT and ABT represent the aortic, thoracic and abdominal tracts, respectively. SV (PUV) reproduces the systemic (pulmonary) venous section. MPA (SPA) is the main (small) pulmonary artery section. PA (PC) represents the pulmonary arteriole (capillary). Pt is the mean intrathoracic pressure. The ela(era), elv(erv) and espt reproduce the left (right) atrial elastance, left (right) ventricular elastance and the septum elastance respectively. MV, AV, TV and PV represent the mitral, aortic, tricuspid and pulmonary valves respectively. PAP (PVP) represents the mean pulmonary arterial (venous) pres-

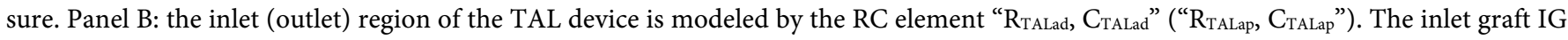
is modeled by the RLC element " $\mathrm{R}_{\text {TALin }}, \mathrm{L}_{\mathrm{TALin}}, \mathrm{C}_{\mathrm{TALin}}$ "; the outlet grafts OG1 (OG2) is modeled by the RLC elements " $\mathrm{R}_{\text {TALala, }} \mathrm{L}_{T A L a l a}, \mathrm{C}_{\mathrm{TALala}}$ " ("R $\mathrm{R}_{\text {TALan }}, \mathrm{L}_{\text {TALan }}, \mathrm{C}_{\text {TALan }}$ "). When TAL assistance is connected in parallel (hybrid) mode the resistance $\mathrm{R}_{\text {TALpab }}$ is set to divert the proper amount of blood to the artificial lung. In panels $\mathrm{A}$ and $\mathrm{B}$, all the diodes are ideal diodes. 
where $E d_{S P T}$ is the septum end-diastolic elastance, $E s_{S P T}$ is the septum end-systolic elastance and $a_{S P T}(t)$ is the activation function described by:

$$
a_{S P T}(t)= \begin{cases}1-\cos \left(\frac{t}{T_{R}} \pi\right) & 0 \leq t \leq T_{R} \\ 1+\cos \left(\frac{t-T_{R}}{T_{T E}-T_{R}} \pi\right) & T_{R}<t \leq T_{T E} \\ 0 & T_{T E}<t \leq T_{D}\end{cases}
$$

$T_{R}$ is the $R$-wave peak time in the ECG signal.

Based on the Equation (1) and Equation (3), we arrive at the following equations:

$$
\left\{\begin{array}{l}
\operatorname{plv}(t)=\frac{e_{S P T}(t) \cdot \operatorname{elv}(t)}{e_{S P T}(t)+e l v(t)} \cdot(v l v(t)-V l o)+\frac{e l v(t)}{e_{S P T}(t)+e l v(t)} \cdot \operatorname{prv}(t) \\
\operatorname{prv}(t)=\frac{e_{S P T}(t) \cdot \operatorname{erv}(t)}{e_{S P T}(t)-\operatorname{erv}(t)} \cdot(\operatorname{vrv}(t)-V r o)-\frac{\operatorname{erv}(t)}{e_{S P T}(t)-\operatorname{erv}(t)} \cdot \operatorname{plv}(t)
\end{array}\right.
$$

where $\operatorname{VIV}(t)(\operatorname{Vrv}(t))$ is the left (right) ventricular volume and $\operatorname{Vlo}(\operatorname{Vro})$ is the residual volume of the left (right) ventricle.

The left (right) atrial behavior is described by the left (right) atrial time-varying elastance ela $(t)(\operatorname{era}(t))$. It is function of the left (right) atrial end-systolic elastance Elas (Eras), the left (right) atrial end-diastolic elastance Elad (Erad) and the left (right) atrial activation function ala $(t)(\operatorname{ara}(t))$ (Figure $1(\operatorname{Panel} \mathrm{A})$ ):

$$
\begin{aligned}
& \operatorname{ela}(t)=\text { Elad }+\frac{\text { Elas }- \text { Elad }}{2} \operatorname{ala}(t) \\
& \operatorname{era}(t)=\text { Erad }+\frac{\text { Eras }- \text { Erad }}{2} \operatorname{ara}(t)
\end{aligned}
$$

The left (right) atrial activation function ala $(t)(\operatorname{ara}(t))$ is defined as follows:

$$
\operatorname{ala}(t)=\operatorname{ara}(t)= \begin{cases}0 & 0<t \leq T_{P B} \\ 1-\cos \left(\frac{t-T_{P B}}{T_{P E}-T_{P B}} 2 \pi\right) & T_{P B}<t \leq T_{P E} \\ 0 & T_{P E}<t \leq T_{D}\end{cases}
$$

where $T_{P B}$ is the starting time of the arterial systole and $T_{P E}$ is the ending time. In determining these points in time, we referred ourselves to the ECG signal.

With the help of Equation (6) and Equation (7) we arrive at the following equations:

$$
\begin{aligned}
& \operatorname{pla}(t)=P \operatorname{Pla}_{0}+e l a(t) \cdot\left(\operatorname{vla}(t)-V_{\text {la0 }}\right) \\
& \operatorname{pra}(t)=\operatorname{Pra}_{0}+\operatorname{era}(t) \cdot\left(\operatorname{vra}(t)-V_{\text {ra0 }}\right)
\end{aligned}
$$

where $\operatorname{vla}(t)(\operatorname{vra}(t))$ is the left (right) atrial volume, $V_{l a 0}\left(V_{r a 0}\right)$ is the residual volume of the left (right) atrium, and $\operatorname{Pla}_{0}\left(\operatorname{Pra}_{0}\right)$ are constants.

Each of the valves (Figure $1($ Panel $\mathrm{A})$ ) is described by a resistance and an ideal diode. 


\subsection{Vascular System Modules}

Our lumped parameter modeling approach of the vascular system comprises lumped components for the vessels in both the systemic and the pulmonary circulation. The lumped components for the systemic circulation, in turn, are subdivided into two groups, viz. the components for the coronary circulation and the elements belonging to the rest of the human body; in the following, we will call the elements describing this main stem of the systemic circulation as trunk of the systemic vasculature.

\subsubsection{Lumped Components Belonging to the Trunk of the Systemic Vasculature}

In our modeling approach, the arterial section of the trunk of the systemic vasculature is described by three individual resistance-inertance-compliance (RLC) lumped components (series of three Windkessel-like [13]): AT describes the arterial, TT the thoracic and ABT the abdominal part of the systemic circulation (Figure 1(Panel A)). The systemic venous (SV) section is described by one resistance-compliance (RC) lumped element [5].

\subsubsection{Lumped Components Belonging to the Coronary Vasculature}

The coronary circulation was modeled as a lumped parameter model based on the intramyocardial pump concept. For a more detailed description, refer to [13] [15].

\subsubsection{Lumped Components Belonging to the Pulmonary Vasculature}

The MPA lumped component describes the larger pulmonary arteries by one resistance-inertance-compliance (RLC) lumped element (Windkessel-like modeling approach [7] [8] [16]). The SPA lumped component describes all the small intra-pulmonary arteries proximal to the arterioles by one resistance-inertance-compliance (RLC) lumped element (Windkessel-like modeling approach [7] [17]). The PA lumped component describes the pulmonary arterioles by solely a single resistance, since the arterioles are relatively stiff, and, moreover, the inertial forces are negligible [7] [16]. The PC lumped component describes the pulmonary capillary bed by solely a single resistance as before [7] [16].

\subsection{Description of the Newly-Developed Thoracic Artificial Lung Software}

A TAL is used as a partial or even an almost full replacement of the native pulmonary circulation. Unlike other artificial lung devices, it doesn't contain a blood pump; instead, the flow of blood is driven by the right ventricle. As mentioned earlier, there are three modes of operation possible, viz.

- parallel mode,

- series mode,

- hybrid mode.

In each of the above modes of operation, venous blood from the proximal end of the pulmonary artery is conducted through a tubular graft (cannula), the inlet graft IG, to 
the inlet connection nozzle of the TAL device. Within the TAL, the blood is oxygenated. As can be seen in Figure 1(Panel B), the outlet of the TAL device is attached to the input of a Y-connector with two outlet nozzles for the effluent blood. The further way of proceeding is dependent on the particular mode of operation:

- In the hybrid mode, tubular grafts are attached to both outlet nozzles (cf. OG1 and OG2 Panel B). Graft OG1 conducts blood to the distal end of the pulmonary artery, whereas graft OG2 conducts blood to the left atrium. As depicted in figure (Panel $B$ ), all three switches $S_{W_{S 1}}, S_{S_{2}}$, and $S_{W_{P 1}}$ are in position $O N$. In this mode, the pulmonary artery must not be occluded (no artery ligation).

- In the parallel mode, only one outlet graft is required (OG1). Its upstream end is attached to one of the two outlet nozzles of the Y-connector, whereas the other outlet nozzle is sealed. The downstream end of the graft is positioned within the left atrium. In the parallel mode configuration, the switches $\mathrm{SW}_{\mathrm{S} 1}$ and $\mathrm{SW}_{\mathrm{S} 2}$ are in position $\mathrm{ON}$, but the switch $\mathrm{SW}_{\mathrm{P} 1}$ is in position OFF. In this mode, the pulmonary artery must not be occluded (no artery ligation).

- In the serial mode, only one outlet graft is required (OG2 in Figure 1(Panel B)). Its upstream end is again attached to one of the two outlet nozzles of the Y-connector, whereas the other outlet nozzle is sealed; its downstream end is inserted into the distal region of the pulmonary artery. Moreover, a decisive measure in this mode is the occlusion (artery ligation) of the pulmonary artery between its proximal and distal region. Hence, in the series mode configuration, the switch $S_{\mathrm{S} 1}$ must be in position OFF. The switch $\mathrm{SW}_{\mathrm{S} 2}$ must also be in position OFF, while the switch $\mathrm{SW}_{\mathrm{P} 1}$ is in position $\mathrm{ON}$.

The newly-developed TAL module is, as all already existing modules of CARDIOSIM ${ }^{\odot}$, based on a lumped parameter modeling approach with resistance-inertance-compliance (RLC) elements, resistance-compliance (RC) elements and resistance (R) elements as lumped components [6] [7] [8] [9].

The individual branches of the TAL configuration in figure represent the constituents of the TAL as follows:

- The inlet graft IG is modeled by the RLC element " $\mathrm{R}_{\mathrm{TALin}}, \mathrm{L}_{\mathrm{TALL}}, \mathrm{C}_{\mathrm{TALin}}$ " and

- the outlet grafts OG1 (OG2) by the RLC elements " $\mathrm{R}_{\text {TALala, }} \mathrm{L}_{\mathrm{TALala}}, \mathrm{C}_{\text {TALala }}$ " (" $\mathrm{R}_{\mathrm{TALan}}$, $\mathrm{L}_{\text {TALan }}, \mathrm{C}_{\text {TALan }}$ ").

- The TAL device which is the central part of the configuration, can be subdivided into three sections, viz. the inlet region, the fiber bundle, and the outlet region. In the entire flow domain of the TAL device, the inertial forces are insignificant. It is thus permissible to omit inertances in our circuit diagram. The inlet (outlet) region of the TAL device is modeled by the RC element " $\mathrm{R}_{\text {TALad }}, \mathrm{C}_{\text {TALad }}$ " (" $\mathrm{R}_{\text {TALap }}, \mathrm{C}_{\text {TALap }}$ "). The fiber bundle has a very low compliance which can justifiably be neglected. As a consequence, only its resistance to flow must be considered which is represented in figure solely by one element, viz. the resistor $\mathrm{R}_{\text {TALb }}$.

- The resistance $\mathrm{R}_{\mathrm{TALpab}}$ is set to divert the proper amount of blood to the artificial lung. 


\subsection{Intrathoracic and Intra-Abdominal Pressure-A Key Issue in Our Modeling Approach}

In building the above-described model, we put much emphasis in finding fair values for the extramural pressure of the various conduits for blood, such as arteries, veins, capillaries, and grafts.

- It is obvious that extramural pressure of the grafts and all regions of the TAL will be the ambient pressure.

- It can be justifiably assumed that the extramural pressure of all constituents of the pulmonary circulation and of the lumped elements AT and TT (Figure 1(Panel A)) is identical with the intrathoracic pressure $p t(t)$ which is varying with time. In our modeling approach, we use instead the mean intrathoracic pressure $P t$ which is defined as:

$$
P t=\frac{1}{T} \int_{0}^{T} p_{t}(t) \mathrm{d} t
$$

where $T$ is the duration of a ventilatory cycle and $p t(t)$ is instantaneous values of the time-varying thoracic pressure [18]. By changing the $P t$ value it is possible to simulate and analyze the effects of mechanical ventilation will have on energetic/hemodynamic cardiovascular variables [7] [18] [19].

- The extramural pressure of the blood vessels which are modeled by the lumped elements $\mathrm{ABT}$ and SV (Figure $1(\operatorname{Panel} \mathrm{A})$ ) is equal to the intra-abdominal pressure (the steady state pressure concealed within the abdominal cavity). Investigations of the intra-abdominal pressure are an important field of current research. However, highly reliable data are not yet available. In the future we will deal with this problem area intensively, but at this stage of development, we made the justifiable assumption that the extramural pressure of $\mathrm{ABT}$ and $\mathrm{SV}$ is identical with the ambient pressure.

\subsection{Experimental Method}

Critically-ill patients suffering from various severe pulmonary diseases may require partial or even total respiratory support. A wide-spread measure to provide respiratory support is the application of mechanical ventilation. However, there are a number of alternatives. We will concentrate here on one of them, viz. the thoracic artificial lung. In the treatment of patients with end-stage lung disease who need lung transplantation, for instance, the application of a TAL is a sheer need to bridge the critical time until a donor lung is available, since mechanical ventilation could be a significant risk factor for lung transplant recipients. When clinicians adopt respiratory support measures as mentioned above, they must bear in mind that these procedures will have potent effects on the cardiovascular system. Hence, it is extremely important to provide them with a fair quantitative knowledge of these effects. Our investigations aimed at obtaining this information by carrying out computer simulation experiments. In these simulation experiments, the intrathoracic pressure and its variations played a particularly important role [17]. In our simulation studies, the mean intrathoracic pressure Pt has been chosen 
as the varying reference parameter; for the assessment of the effects of $P t$ on the cardiovascular system, the following quantities are simulated:

- energetic parameters, viz. left and right ventricular external work (EW), pressurevolume area (PVA), cardiac mechanical efficiency (CME) [11] [20] [21] and

- specific hemodynamic variables, such as cardiac output (CO), mean pulmonary arterial pressure (PAP) and mean pulmonary venous (PVP) pressure.

In particular, we performed two different kinds of simulation studies to investigate

- the effects of mechanical ventilation on the cardiovascular system [22] and

- the effects of the application of a thoracic artificial lung on the cardiovascular system, under the assumption that no mechanical ventilation takes place [6] [7].

The above-mentioned two different respiratory support measures have distinct effects on the cardiovascular system. Not only two different ranges for Pt must be defined for the two aforementioned kinds of investigations, but also there are further differences as will become apparent in the following overview of the simulation methodologies:

\subsubsection{Overview of the Simulation Studies of Interactions between Mechanical Ventilation (without TAL) and the Cardiovascular System}

In normal quiet breathing, the mean intrathoracic pressure will take on negative values relative to the local atmospheric or ambient pressure. In our studies, however, we assume that in the treatment of a patient a mechanical ventilator is used and positive pressure ventilation is applied. We defined a range of $P t$ from $-6[\mathrm{mmHg}]$ to +6 [mmHg] which comprises all the possible values of $P t$ ranging from normal quiet breathing to positive pressure ventilation. We started with simulation runs at baseline conditions $(P t=-6[\mathrm{mmHg}]$ and $P t=+6[\mathrm{mmHg}])$; afterwards we carried out simulation runs for varying levels of $P t$ ranging from $-6[\mathrm{mmHg}]$ to $+6[\mathrm{mmHg}]$ in steps of 1 [mmHg] [18].

\subsubsection{Overview of the Simulation Studies of Interactions between TAL Assistance (without and with Mechanical Ventilation) and the Cardiovascular System}

In our studies we assume that in the treatment of a patient a thoracic artificial lung is applied; these studies involve both 1) simulation studies without mechanical ventilation and 2) the more hypothetical case of simulation studies with simultaneous mechanical ventilation. We defined a range of $P t$ from $-6[\mathrm{mmHg}]$ to $+6[\mathrm{mmHg}]$ which comprises all the possible values of $P t$ from ranging from normal quiet breathing in the case of TAL assistance without mechanical ventilation to the more hypothetical case of positive pressure ventilation. As before, we performed simulation runs at baseline conditions $(P t=-6[\mathrm{mmHg}]$ and $P t=+6[\mathrm{mmHg}])$; However, we must bear in mind that all simulation runs for the positive values of $P=+6[\mathrm{~mm} \mathrm{Hg}]$ exclusively refer to the more hypothetical case of combined and simultaneous use of TAL assistance and mechanical ventilation.

\section{Results}

As adumbrated in the previous section, we carried out two categories of simulation 
studies, viz.

- simulation studies which refer to a ventilated patient without using a TAL (we will call this category briefly "MV without TAL") and

- simulation studies referring to TAL assistance without mechanical ventilation and to the more hypothetical case with mechanical ventilation (we will call this category briefly "TAL assisted").

The results of our simulation studies will preferably be presented in graphical form to provide physicians in an easily interpretable way with a deep understanding of the consequences of the chosen respiratory assistance strategy will have for the patient's cardiovascular system.

\subsection{Simulation Results-Category "MV without TAL"}

As already mentioned earlier, the simulations referring to the category " $\mathrm{MV}$ without TAL" have been carried out for values of Pt varying from $-6[\mathrm{mmHg}]$ to $+6[\mathrm{mmHg}]$ in steps of 1 [mmHg]. The simulation results comprise the totality of the commonly used quantities for the description of the ventricular energetics and the hemodynamic consequence of mechanical ventilation.

We graphically present here only a selection of those simulation results that illustrate the main features relating to energetics and hemodynamics, viz. the following quantities: the left ventricular pressure-volume area PVA, the right ventricular CME, the mean pulmonary venous pressure PVP, and the mean cardiac output CO.

Although these selected quantities which are shown in Figure 2 are only a small choice of the results obtained with our simulation studies, they nevertheless can impart a fair overview of the energetic and hemodynamic implications of mechanical ventilation.

In Figure 2, where the above-mentioned quantities are normalized values in the sense that we:

- first calculated for each quantity the difference between the maximal and minimal simulated value, which we will call "maximal variation" and then

- determined the ratio of the individual simulated values to this "maximal variation".

\subsection{Simulation Results-Category "TAL assistance"}

Figure 3 depicts simulation results which refer to the case of TAL assistance. The TAL was applied in parallel and in hybrid mode. The mean intrathoracic pressure was set to +6 and $-6[\mathrm{mmHg}$ ], but we have to bear in mind that the setting of the intrathoracic pressure at $+6[\mathrm{mmHg}]$ does only refer to the more hypothetical case of a TAL use with simultaneous mechanical ventilation. The simulations were performed for varying

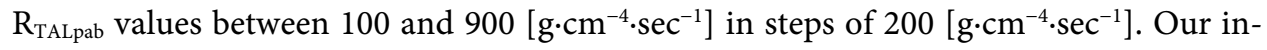
vestigations comprised simulation runs for TAL assistance in both parallel and hybrid mode. In the graphical representation of the simulation results in Figure 3, we confined ourselves to the following two quantities viz. the mean pulmonary arterial pressure (Panel [a]) and the mean cardiac output (Panel [b]). 


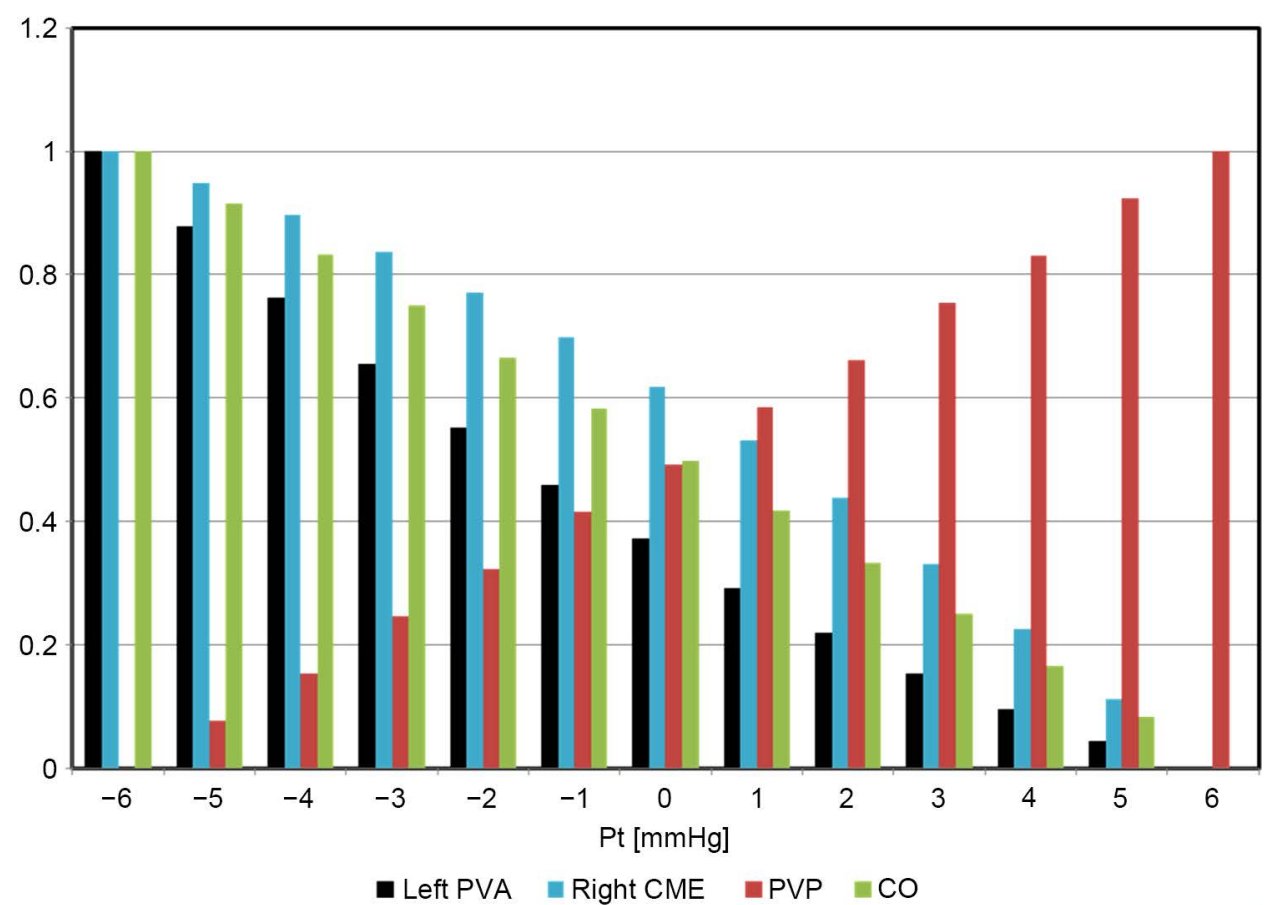

Figure 2. Bar diagram of the left ventricular PVA, right ventricular cardiac mechanical efficiency (CME), PVP and CO referring to mechanical ventilation without thoracic artificial lung.

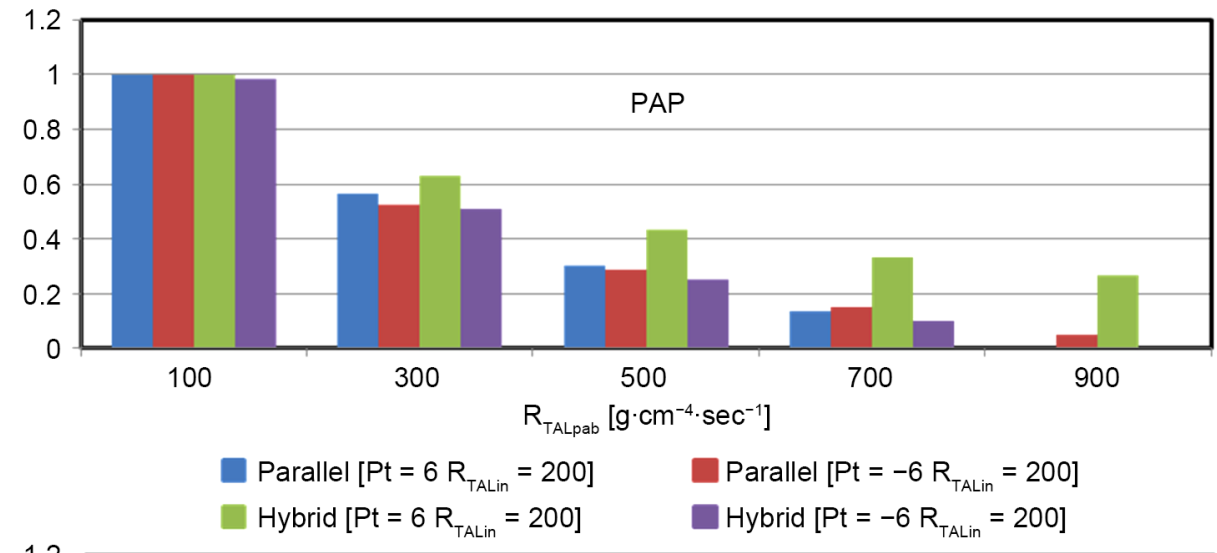

(a)

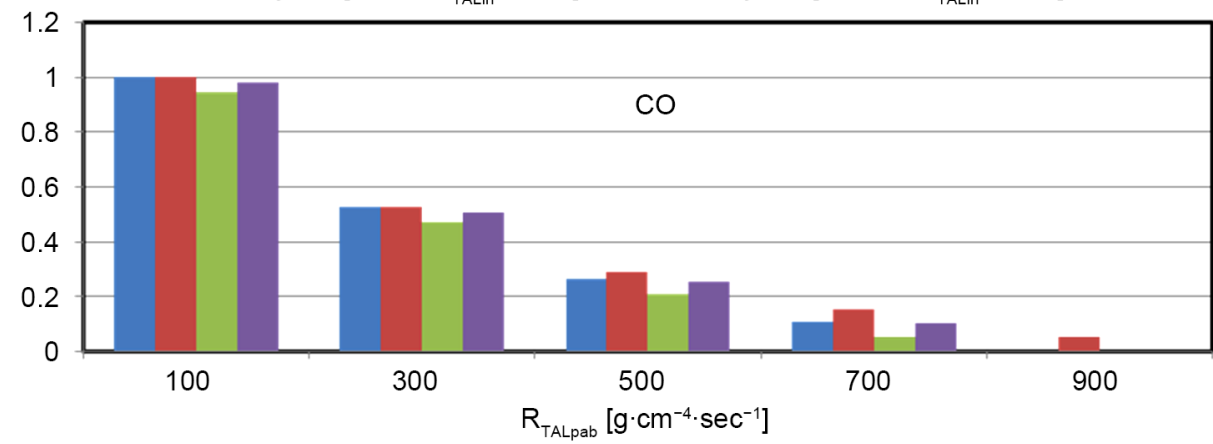

(b)

Figure 3. Simulations studies with the application of a TAL; simulations they were $P t$ to -6 [mmHg] and $+6[\mathrm{mmHg}]$ and for the parallel and hybrid mode of the TAL. For each $P t$ value, PAP (panel [a]) and CO (panel [b]) have been normalized; $\mathrm{R}_{\text {TALin }}\left(\mathrm{C}_{\text {TALin }}\right.$ ) was set to 200 $\left[\mathrm{g} \cdot \mathrm{cm}^{-4} \cdot \mathrm{sec}^{-1}\right]\left(0.5\left[\mathrm{~cm}^{3} \cdot \mathrm{mmHg}^{-1}\right]\right)$. 
In the bar diagram of Figure 3, these two quantities (PAP and CO) are represented for the simulation runs referring to the mean intrathoracic pressure $+6(-6)[\mathrm{mmHg}]$ as normalized values in the sense that has previously been described. As can be seen in Figure 3, both quantities PAP (Panel [a]) and CO (Panel [b]) decrease as $\mathrm{R}_{\text {TALpab }}$ increases; this behavior is true for TAL assistance in parallel as well as in hybrid mode.

The simulation results of Figure 4 and Figure 5 refer to important energetic parameters, viz. the left and right ventricular external work (Figure 4) and the left and right ventricular pressure-volume area (Figure 5). The investigations involve simulations for all possible modes of operation, viz. the series mode, the parallel mode, and the hybrid mode.

They carried out for the mean intrathoracic pressure values of +6 and $-6[\mathrm{mmHg}]$, but we have again to bear in mind that the setting of the intrathoracic pressure at +6 [mmHg] does only refer to the more hypothetical case of a TAL use with simultaneous mechanical ventilation. In all modes of operation, we carried out separate simulation runs for $\mathrm{R}_{\mathrm{TALin}}=100\left[\mathrm{~g} \cdot \mathrm{cm}^{-4} \cdot \mathrm{sec}^{-1}\right]$ and $\mathrm{R}_{\mathrm{TALin}}=10\left[\mathrm{~g} \cdot \mathrm{cm}^{-4} \cdot \mathrm{sec}^{-1}\right]$, whereby $\mathrm{C}_{\mathrm{TALLin}}$ was set to $0.5\left[\mathrm{~cm}^{3} \cdot \mathrm{mmHg}^{-1}\right]$. In the cases of parallel and hybrid mode $\mathrm{R}_{\mathrm{TALpab}}$ was assumed to be $250\left[\mathrm{~g} \cdot \mathrm{cm}^{-4} \cdot \mathrm{sec}^{-1}\right]$.

The bar diagrams in Figure 4 depict percent changes in the left and right ventricular EW, whereas Figure 5 shows percent changes in the left and right ventricular PVA. In both figures, the lengths of the rectangular bars are proportional to the percent changes of the individual quantities in the sense that these percent changes represent the relative

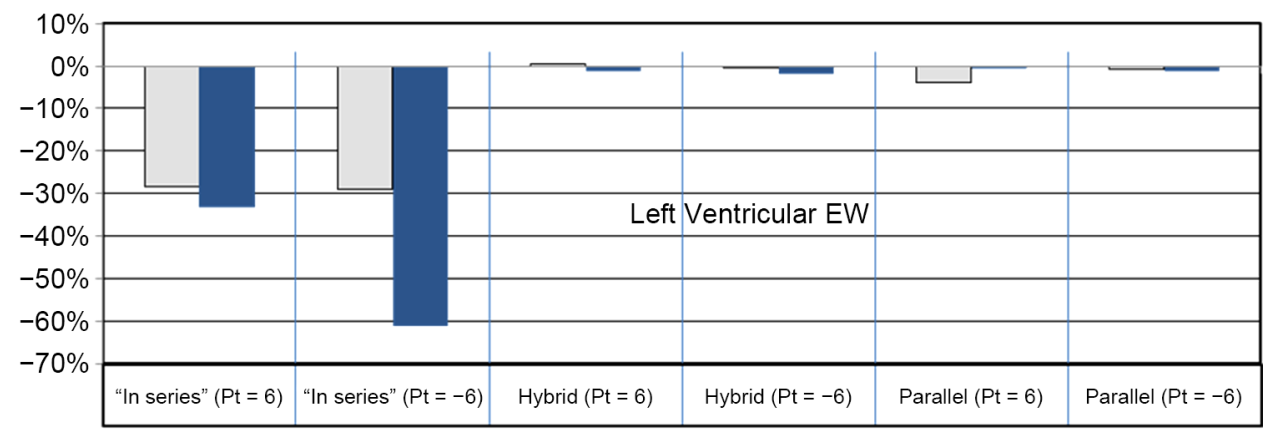
$\mathrm{R}_{\mathrm{TALin}}=100\left[\mathrm{~g} \cdot \mathrm{cm}^{-4} \cdot \mathrm{sec}^{-1}\right]$
$\mathrm{R}_{\mathrm{TALin}}=10\left[\mathrm{~g} \cdot \mathrm{cm}^{-4} \cdot \mathrm{sec}^{-1}\right]$

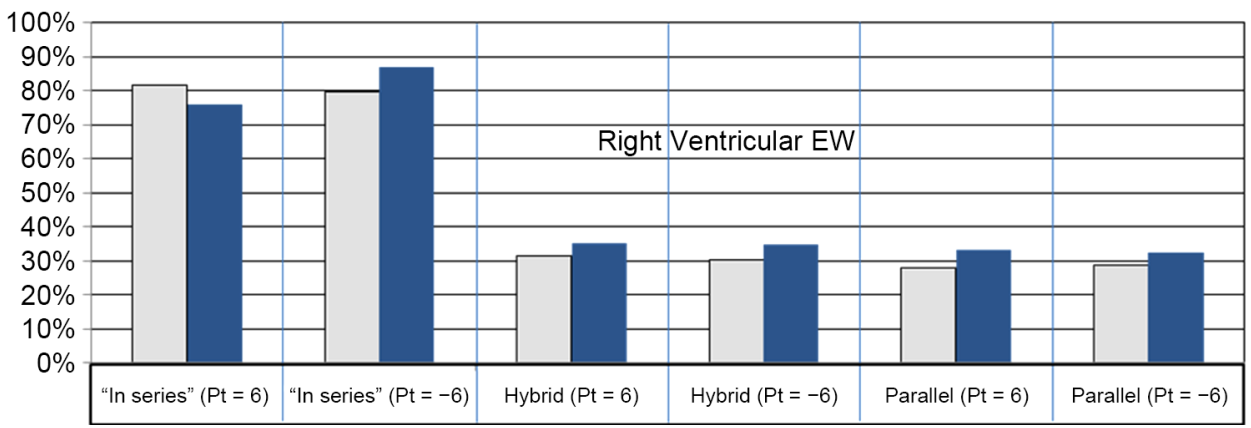

Figure 4. Percent changes of left and right ventricular EW compared with the values which have been obtained for MV in absence of a TAL. The values of $P t$ have been set to +6 and $-6[\mathrm{mmHg}]$. $\mathrm{R}_{\text {TALpab }}$ was set to $250\left[\mathrm{~g} \cdot \mathrm{cm}^{-4} \cdot \mathrm{sec}^{-1}\right]$ and $\mathrm{C}_{\text {TALin }}$ was assumed to be $0.5\left[\mathrm{~cm}^{3} \cdot \mathrm{mmHg}^{-1}\right]$. 


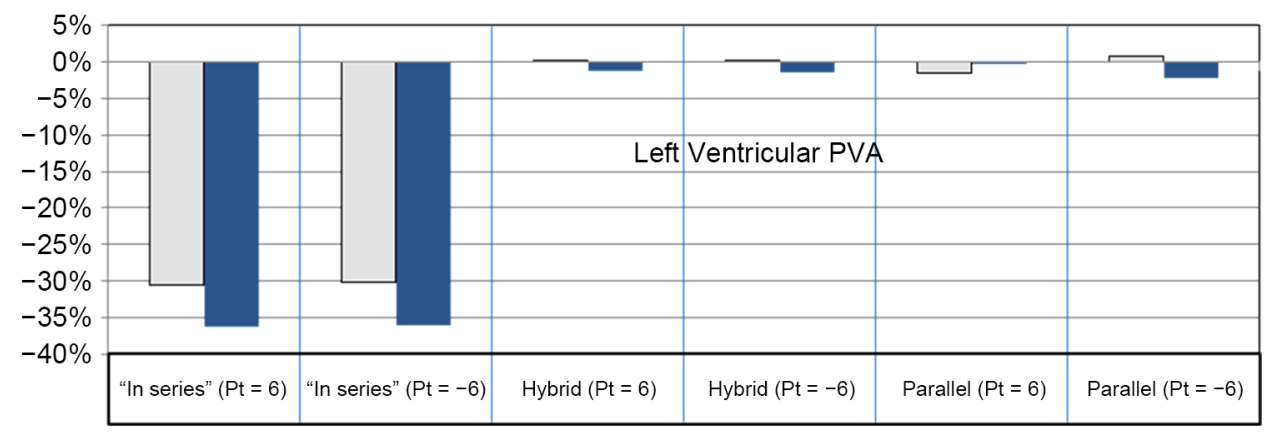

$\mathrm{R}_{\mathrm{TALin}}=100\left[\mathrm{~g} \cdot \mathrm{cm}^{-4} \cdot \mathrm{sec}^{-1}\right]$

$\mathrm{R}_{\mathrm{TALin}}=10\left[\mathrm{~g} \cdot \mathrm{cm}^{-4} \cdot \mathrm{sec}^{-1}\right]$

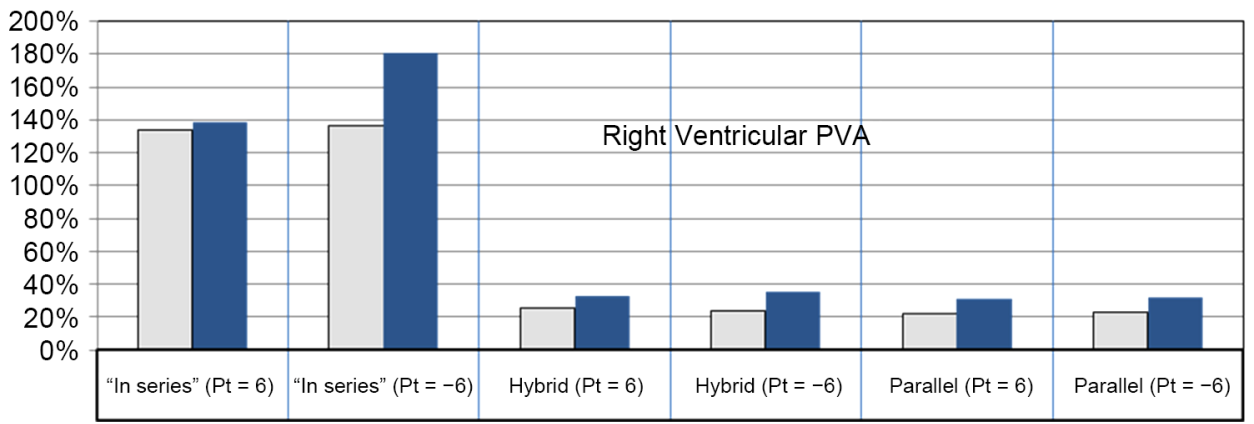

Figure 5. Percent changes of left and right ventricular PVA compared with the values assumed which have been obtained for MV in absence of a TAL. The values of $P t$ have been set to +6 and $-6[\mathrm{mmHg}]$. RTALpab was set to $250\left[\mathrm{~g} \cdot \mathrm{cm}^{-4} \cdot \mathrm{sec}^{-1}\right]$ and $\mathrm{C}_{\text {TALin }}$ was assumed to be $0.5\left[\mathrm{~cm}^{3} \cdot \mathrm{mmHg}^{-1}\right]$.

change between the values which have been obtained for the case of TAL assistance and the corresponding simulation results without an application of a TAL.

In the case of the series mode of TAL assistance, we obtained for both values of $\mathrm{R}_{\text {TALin }}$ $\left(\mathrm{R}_{\mathrm{TALin}}=100\left[\mathrm{~g} \cdot \mathrm{cm}^{-4} \cdot \mathrm{sec}^{-1}\right]\right.$ and $\left.\mathrm{R}_{\mathrm{TALin}}=10\left[\mathrm{~g} \cdot \mathrm{cm}^{-4} \cdot \mathrm{sec}^{-1}\right]\right)$ the largest reductions in left ventricular EW and PVA compared with the two other modes of operation. In contrast, we got in series mode significantly increased values of the right ventricular EW and PVA which exceed the corresponding values in the two other modes of operation. In all cases of TAL assistance, the aforementioned quantities are strongly dependent on the assumed values of $\mathrm{R}_{\mathrm{TALin}}$ (10 and $100\left[\mathrm{~g} \cdot \mathrm{cm}^{-4} \cdot \mathrm{sec}^{-1}\right]$ ).

Some further simulation results of energetic quantities are presented in Table 1; they involve the right cardiac mechanical efficiency CME and the left and right ventricular pressure-volume area PVA. The totality of the values in Table 1 refers to percent changes of the aforementioned quantities in the sense that these percent changes represent the relative change between the values which has been obtained for the case of TAL assistance and the corresponding simulation results for mechanical ventilation without an application of a TAL.

The first and second column (from left) of this table contain the percent changes in the right CME calculated for $P t=+6[\mathrm{mmHg}]$ and $P t=-6[\mathrm{mmHg}]$ and under the assumption that $\mathrm{R}_{\mathrm{TALin}}$ was set to $10\left[\mathrm{~g} \cdot \mathrm{cm}^{-4} \cdot \mathrm{sec}^{-1}\right]$ and subsequently to $\mathrm{R}_{\text {TALin }}=100$ $\left[\mathrm{g} \cdot \mathrm{cm}^{-4} \cdot \mathrm{sec}^{-1}\right]$, whereby we suppose that in all cases $\mathrm{C}_{\text {TALin }}=0.5\left[\mathrm{~cm}^{3} \cdot \mathrm{mmHg}^{-1}\right]$ and that in the case of TAL assistance in parallel and hybrid mode $\mathrm{R}_{\mathrm{TALpab}}=250\left[\mathrm{~g} \cdot \mathrm{cm}^{-4} \cdot \mathrm{sec}^{-1}\right]$. 
Table 1. Simulation results of energetic variables.

\begin{tabular}{lcccccc}
\hline & \multicolumn{2}{c}{ Right CME } & \multicolumn{2}{c}{ Left PVA } & \multicolumn{2}{c}{ Right PVA } \\
\cline { 2 - 6 } & $\mathrm{R}_{\text {TALin }}=10$ & $\mathrm{R}_{\text {TALin }}=100$ & $\mathrm{C}_{\text {TALin }}=0.5$ & $\mathrm{C}_{\text {TALin }}=5.5$ & $\mathrm{C}_{\text {TALin }}=0.5$ & $\mathrm{C}_{\text {TALin }}=5.5$ \\
\hline In series $(P t=+6)$ & $43.6 \%$ & $38.5 \%$ & $-40.7 \%$ & $-48.3 \%$ & $226.9 \%$ & $58.2 \%$ \\
In series $(P t=-6)$ & $-8.8 \%$ & $-18.2 \%$ & $-41.4 \%$ & $-44.0 \%$ & $226.4 \%$ & $70.8 \%$ \\
Hybrid $(P t=+6)$ & $25.6 \%$ & $28.2 \%$ & $-4.3 \%$ & $-15.5 \%$ & $52.2 \%$ & $-17.9 \%$ \\
Hybrid $(P t=-6)$ & $11.3 \%$ & $7.7 \%$ & $-6.5 \%$ & $-8.5 \%$ & $51.6 \%$ & $-12.2 \%$ \\
Parallel $(P t=+6)$ & $24.4 \%$ & $83.3 \%$ & $-5.6 \%$ & $-15.3 \%$ & $47.8 \%$ & $-17.9 \%$ \\
Parallel $(P t=-6)$ & $10.9 \%$ & $7.7 \%$ & $-5.9 \%$ & $-8.4 \%$ & $48.9 \%$ & $-12.5 \%$ \\
\hline
\end{tabular}

The third, fourth, fifth, and sixth column (from left) show the percent changes in left and right PVA. These percent changes were calculated for $P t=+6[\mathrm{mmHg}]$ and $P t=-6$ [mmHg] and under the assumption that in all modes of operation $\mathrm{R}_{\text {TALin }}=200$ $\left[\mathrm{g} \cdot \mathrm{cm}^{-4} \cdot \mathrm{sec}^{-1}\right]$ and that in parallel and hybrid mode $\mathrm{R}_{\text {TALpab }}$ was set to $250\left[\mathrm{~g} \cdot \mathrm{cm}^{-4} \cdot \mathrm{sec}^{-1}\right]$. The third and fifth column (from left) of Table 1 contain simulation results which refer to an assumed value of $\mathrm{C}_{\text {TALin }}=0.5\left[\mathrm{~cm}^{3} \cdot \mathrm{mmHg}^{-1}\right]$, whereas the results in the fourth and sixth column have been obtained by the assumption of $\mathrm{C}_{\text {TALin }}=5.5\left[\mathrm{~cm}^{3} \cdot \mathrm{mmHg}^{-1}\right]$. The simulation results comprised in Table 1 offer cardiologists deep insights into the hemodynamic consequences of the use of a TAL. In particular, for the mean intrathoracic pressure $P t=+6[\mathrm{mmHg}$ ] (hypothetical case of a TAL use with simultaneous mechanical ventilation) the right CME increases as a consequence of the application of the TAL in all modes of operation, whereas for $P t=-6[\mathrm{mmHg}]$ the results in the first and second column (from the left) show that the right CME decreases in series mode and increases in parallel and hybrid mode. The simulated data in the fifth and sixth column (from the left) show that values for the right PVA are strongly dependent on changes of the assumed values of compliance $\mathrm{C}_{\mathrm{TALin}}$ for all TAL assistance modes and for both mean intrathoracic pressure values $P t=+6[\mathrm{mmHg}]$ and $P t=-6[\mathrm{mmHg}]$.

\section{Conclusions}

Patients with severe respiratory failure are dependent on the application of respiratory assistance devices to ensure sufficiently high concentrations of $\mathrm{O}_{2}$ and $\mathrm{CO}_{2}$ in the blood. However, these devices will have serious consequences on the other parts of the human body, especially on the cardiovascular system, and we used our CARDIOSIM ${ }^{\odot}$ software system to investigate these consequences. In this paper, we concentrated on simulation studies of the effects evoked by TAL assistance on cardiac energetic and some other important circulatory parameters. The simulation results presented above show that in every modes of TAL assistance there exists a strong dependency on the input variables $\mathrm{R}_{\text {TALin }}$ and $\mathrm{C}_{\text {TALin }}$ and on the value of the mean intrathoracic pressure which has been assumed for a given situation.

At present, our simulation activities are based on a rather coarse modeling approach. 
In particular, our approach does not yet sufficiently take into account the details of the complicated anatomic structure of the cardiovascular system and is still based on the simplifying assumption of a uniform intrathoracic pressure. The simulation results obtained with our model can thus only be regarded as relatively coarse approximations. Nonetheless, it proved that the results of our present simulation studies has provided clinicians with valuable insights on how to quantitatively assess the effects of assisted respiration on the cardiovascular system.

We will improve our CARDIOSIM ${ }^{\odot}$ numerical simulator step by step. The next step will be the development of a module which will allow us to describe the variations of the extramural pressure of the blood vessels throughout the human body (intrathoracic, intrapulmonary, and intra-abdominal pressure). This future work will be validated by using an already existing wealth of recorded clinical data.

\section{Acknowledgements}

This work was supported by the Italian Ministry of Education, University and Research (M.I.U.R.) Flagship InterOmics Project (cod. PB05).

\section{References}

[1] Ochiai, Y., McCarthy, P.M., Smedira, N.G., Banbury, M.K., Navia, J.L., Feng, J., Hsu, A.P., Yeager, M.L., Buda, T., Hoercher, K.J., Howard, M.W., Takagaki, M., Doi, K. and Fukamachi, K. (2002) Predictors of Severe Right Ventricular Failure after Implantable Left Ventricular Assist Device Insertion: Analysis of 245 Patients. Circulation, 106, 198-202.

[2] Mitchell, J.R., Sas, R., Zuege, D.J., Doig, C.J., Smith, E.R., Whitelaw, W.A., Tyberg, J.V. and Belenkie, I. (2005) Ventricular Interaction during Mechanical Ventilation in Closed-Chest Anesthetized Dogs. Canadian Journal of Cardiology, 21, 73-81.

[3] Colquitt, R.B., Colquhoun, D.A. and Thiele, R.H. (2011) In Silico Modelling of Physiologic Systems. Best Practice \& Research. Clinical Anaesthesiology, 25, 499-510. http://dx.doi.org/10.1016/j.bpa.2011.08.006

[4] De Lazzari, C., Mimmo, R., et al. (1991) CARDIOSIM@ Cardiovascular Software Simulator Developed at the Institute of Clinical Physiology, Rome, Italy. C.N.R. National Research Council. https://cardiosim.dsb.cnr.it/

[5] Ferrari, G., De Lazzari, C., Mimmo, R., Tosti, G. and Ambrosi, D. (1992) A Modular Numerical Model of the Cardiovascular System for Studying and Training in the Field of Cardiovascular Physiopathology. Journal of Biomedical Engineering, 14, 91-107. http://dx.doi.org/10.1016/0141-5425(92)90014-C

[6] De Lazzari, C., Genuini, I., Quatember, B. and Fedele, F. (2014) Mechanical Ventilation and Thoracic Artificial Lung Assistance during Mechanical Circulatory Support with PUCA Pump: In Silico Study. Computer Methods and Programs in Biomedicine, 113, 642-654. http://dx.doi.org/10.1016/j.cmpb.2013.11.011

[7] De Lazzari, C., Genuini, I., Pisanelli, D.M., D’Ambrosi, A. and Fedele, F. (2014) Interactive Simulator for e-Learning Environments: A Teaching Software for Health Care Professionals. BioMedical Engineering OnLine, 13, 172. http://dx.doi.org/10.1186/1475-925X-13-172

[8] Boschetti, F., Perlman, C.E., Cook, K.E. and Mockros, L.F. (2000) Hemodynamic Effects of Attachment Modes and Device Design a Thoracic Artificial Lung. ASAIO Journal, 46, 4248. http://dx.doi.org/10.1097/00002480-200001000-00013 
[9] Perlman, C.E. and Mockros, L.F. (2007) Hemodynamic Consequences of Thoracic Artificial Lung Attachment Configuration: A Computational Model. ASAIO Journal, 53, 50-64. http://dx.doi.org/10.1097/01.mat.0000249867.39647.43

[10] Kuo, A.S., Perlman, C.E., Mockros, L.F. and Cook, K.E. (2008) Pulmonic Valve Function during Thoracic Artificial Lung Attachment. ASAIO Journal, 54, 197-202. http://dx.doi.org/10.1097/MAT.0b013e318164e485

[11] Sagawa, K., Maughan, L., Suga, H. and Sunagawa, K. (1988) Cardiac Contraction and the Pressure-Volume Relationships. Oxford University Press, New York.

[12] De Lazzari, C. (2012) Interaction between the Septum and the Left (Right) Ventricular Free Wall in Order to Evaluate the Effects on Coronary Blood Flow: Numerical Simulation. Computer Methods in Biomechanics and Biomedical Engineering, 15, 1359-1368. http://dx.doi.org/10.1080/10255842.2011.597354

[13] De Lazzari, C., Neglia, D., Ferrari, G., Bernini, F., Micalizzi, M., L’Abbate, A. and Trivella, M.G. (2009) Computer Simulation of Coronary Flow Waveforms during Caval Occlusion. Methods of Information in Medicine, 48, 113-122. http://dx.doi.org/10.3414/me0539

[14] Maughan, W.L., Sunagawa, K. and Sagawa, K. (1987) Ventricular Systolic Interdependence: Volume Elastance Model in Isolated Canine Hearts. American Journal of Physiology, 253, H1381-H1390.

[15] De Lazzari, C., L’Abbate, A., Micalizzi, M., Trivella, M.G. and Neglia, D. (2014) Effects of Amlodipine and Adenosine on Coronary Haemodynamics: In Vivo Study and Numerical Simulation. Computer Methods in Biomechanics and Biomedical Engineering, 17, 16421652. http://dx.doi.org/10.1080/10255842.2012.761691

[16] Shi, Y., Lawford, P. and Hose, R. (2011) Review of Zero-D and 1-D Models of Blood Flow in the Cardiovascular System. BioMedical Engineering OnLine, 10, 33. http://dx.doi.org/10.1186/1475-925x-10-33

[17] Marini, J.J., Culver, B.H. and Butler, L. (1981) Mechanical Effect of Lung Distension with Positive Pressure on Cardiac Function. The American Review of Respiratory Disease, 124, 382-386.

[18] De Lazzari, C., Darowski, M., Ferrari, G., Clemente, F. and Guaragno, M. (2000) Computer Simulation of Haemodynamic Parameters Changes with Left Ventricle Assist Device and Mechanical Ventilation. Computers in Biology and Medicine, 30, 55-69. http://dx.doi.org/10.1016/S0010-4825(99)00026-8

[19] De Lazzari, C., Darowski, M., Ferrari, G., Pisanelli, D.M. and Tosti, G. (2006) Modelling in the Study of Interaction of Hemopump Device and Artificial Ventilation. Computers in Biology and Medicine, 36, 1235-1251. http://dx.doi.org/10.1016/j.compbiomed.2005.08.001

[20] De Lazzari, C., Darowski, M., Ferrari, G., Pisanelli, D.M. and Tosti, G. (2006) The Impact of Rotary Blood Pump in Conjunction with Mechanical Ventilation on Ventricular Energetic Parameters: Numerical Simulation. Methods of Information in Medicine, 45, 574-583.

[21] De Lazzari, C., Darowski, M., Wolski, P., Ferrari, G., Tosti, G. and Pisanelli, D.M. (2005) In Vivo and Simulation Study of Artificial Ventilation Effects on Energetic Variables in Cardiosurgical Patients. Methods of Information in Medicine, 44, 98-105.

[22] Duke, G.J. (1999) Cardiovascular Effects of Mechanical Ventilation. Critical Care \& Resuscitation, 1, 388-399. 


\section{Abbreviations}

\begin{tabular}{|c|c|c|c|}
\hline TAL & Thoracic Artificial Lung & $\operatorname{vlv}(t)(\operatorname{vrv}(t))$ & Left (right) ventricular volume \\
\hline MV & Mechanical ventilation & Vlo (Vro) & $\begin{array}{l}\text { Residual volume of the left } \\
\text { (right) ventricle }\end{array}$ \\
\hline COPD & $\begin{array}{l}\text { Chronic Obstructive } \\
\text { Pulmonary Disease }\end{array}$ & $\operatorname{plv}(t)(\operatorname{prv}(t))$ & Left (right) ventricular pressure \\
\hline ARDS & $\begin{array}{l}\text { Acute Respiratory } \\
\text { Distress Syndrome }\end{array}$ & $\operatorname{ela}(t)(\operatorname{era}(t))$ & $\begin{array}{l}\text { Left (right) atrial time-varying } \\
\text { elastance }\end{array}$ \\
\hline VAD & Ventricular Assist Device & Elas $($ Eras $)$ & $\begin{array}{l}\text { Left (right) atrial end-systolic } \\
\text { elastance }\end{array}$ \\
\hline EW & External Work & Elad (Erad) & $\begin{array}{l}\text { Left (right) atrial end-diastolic } \\
\text { elastance }\end{array}$ \\
\hline PVA & Pressure Volume Area & $\operatorname{ala}(t)(\operatorname{ara}(t))$ & $\begin{array}{l}\text { Left (right) atrial activation } \\
\text { function }\end{array}$ \\
\hline CME & Cardiac Mechanical Efficiency & $\operatorname{vla}(t)(\operatorname{vra}(t))$ & Left (right) atrial volume \\
\hline $\mathrm{CO}$ & Cardiac Output & $\operatorname{pla}(t)(\mathrm{p} r a(t))$ & Left (right) atrial pressure \\
\hline PAP (PVP) & $\begin{array}{l}\text { Mean Pulmonary Arterial } \\
\text { (Venous) Pressure }\end{array}$ & $V l a_{0}\left(V r a_{0}\right)$ & $\begin{array}{l}\text { Residual volume of the left } \\
\text { (right) atrium }\end{array}$ \\
\hline CARDIOSIM $^{\odot}$ & $\begin{array}{l}\text { Software Simulator of the } \\
\text { Cardiovascular System }\end{array}$ & $\mathrm{AT}(\mathrm{TT})[\mathrm{ABT}]$ & $\begin{array}{l}\text { Arterial, (thoracic) [abdominal] } \\
\text { part of the systemic circulation }\end{array}$ \\
\hline $\operatorname{elv}(t)(\operatorname{erv}(t))$ & $\begin{array}{l}\text { Left (right) time-varying } \\
\text { ventricular elastance }\end{array}$ & $\mathrm{PA}(\mathrm{PC})$ & $\begin{array}{c}\text { Pulmonary arterioles } \\
\text { (pulmonary capillary bed) }\end{array}$ \\
\hline Elvs $($ Ervs $)$ & $\begin{array}{l}\text { Left (right) ventricular } \\
\text { end-systolic elastance }\end{array}$ & RLC (RC) & $\begin{array}{l}\text { Resistance-inertance-compliance } \\
\quad \text { (resistance-compliance) }\end{array}$ \\
\hline Elvd $($ Ervd) & $\begin{array}{l}\text { Left (right) ventricular } \\
\text { end-diastolic elastance }\end{array}$ & SV (PUV) & $\begin{array}{l}\text { Systemic (pulmonary) venous } \\
\text { section }\end{array}$ \\
\hline $\operatorname{alv}(t)(\operatorname{arv}(t))$ & $\begin{array}{l}\text { Left (right) ventricular } \\
\text { activation function }\end{array}$ & SPA & $\begin{array}{l}\text { Small intra-pulmonary arteries } \\
\text { proximal to the arterioles }\end{array}$ \\
\hline $\mathrm{T}_{\mathrm{D}}$ & Duration of the ECG signal & MPA (SPA) & $\begin{array}{l}\text { Main (small) pulmonary } \\
\text { artery section }\end{array}$ \\
\hline $\mathrm{T}_{\mathrm{TE}}\left(\mathrm{T}_{\mathrm{T}}\right)$ & $\begin{array}{c}\text { End ventricular systolic } \\
\text { (T-wave peak) time in ECG signal }\end{array}$ & $P t$ & Mean intrathoracic pressure \\
\hline$E d_{S P T}\left(E s_{S P T}\right)$ & $\begin{array}{l}\text { Septum end-diastolic elastance } \\
\text { (septum end-systolic elastance) }\end{array}$ & IG & Inlet Graft \\
\hline$a_{S P T}(t)$ & Septum activation function & OG1/OG2 & Outlet Graft \\
\hline $\mathrm{T}_{\mathrm{R}}$ & R-wave peak time in ECG signal & $\mathrm{R}_{\text {TALpab }}$ & $\begin{array}{l}\text { Is set to divert the proper amount } \\
\text { of blood to the artificial lung }\end{array}$ \\
\hline
\end{tabular}


Submit or recommend next manuscript to SCIRP and we will provide best service for you:

Accepting pre-submission inquiries through Email, Facebook, LinkedIn, Twitter, etc. A wide selection of journals (inclusive of 9 subjects, more than 200 journals)

Providing 24-hour high-quality service

User-friendly online submission system

Fair and swift peer-review system

Efficient typesetting and proofreading procedure

Display of the result of downloads and visits, as well as the number of cited articles

Maximum dissemination of your research work

Submit your manuscript at: http://papersubmission.scirp.org/

Or contact mnsms@scirp.org 